\title{
Gel properties of gelatin from clown featherback (Chitala ornata) skin: Effect of swelling time
}

\author{
Phanat Kittiphattanabawon ${ }^{1 *}$, Soottawat Benjakul ${ }^{2}$ \\ ${ }^{1}$ Department of Food Science and Technology, Faculty of Technology and Community Development, Thaksin University, Phatthalung Campus, \\ Phatthalung, Thailand, '2Department of Food Technology, Faculty of Agro-industry, Prince of Songkla University, Hat Yai, Songkhla, Thailand
}

\section{A B S T R A C T}

\begin{abstract}
Characteristics and gel properties of gelatin from the skin of clown featherback (Chitala ornata J. E. Gray, 1831) as affected by different swelling time $(0,15,30,60,120$ and $240 \mathrm{~min})$ were investigated. The highest and lowest recoveries of gelatin were found when the gelatin extracted from skin swollen for 15 and $30 \mathrm{~min}(80.98-81.52 \%)$ and $240 \mathrm{~min}(40.47 \%)$, respectively. Gelatin extracted from swollen skin had $\alpha_{-}, \beta$ - and $\gamma$-chains as the major component, while their major components of gelatin extracted from non-swollen skin were degraded into smaller peptides. The swelling time did not affect the gel strength $(330-342 \mathrm{~g})$, gelling temperature (23.29-23.76 $\left.{ }^{\circ} \mathrm{C}\right)$ and gelling time (12.03-12.23 min). In contrast, gelatin extracted from non-swollen skin showed poor recovery $(9.80 \%)$ and gel strength $(82 \mathrm{~g})$, gelling temperature $\left(12.8^{\circ} \mathrm{C}\right)$ and cannot be set at $25^{\circ} \mathrm{C}$ within $60 \mathrm{~min}$. Therefore, the skin should be swollen with $0.1 \mathrm{M}$ acetic acid for 15 min before extraction.
\end{abstract}

Keywords: Chitala ornata; Clown featherback; Gel property; Gelatin; Swelling time

\section{INTRODUCTION}

Gelatin is a collagen derivative obtained from thermal denaturation of collagen by extraction with water at temperature higher than its thermal denaturation. Skin, bone and scale generated as by-products from fish processing, are wildly used for gelatin production. Due to the religious restriction of Muslim, Hindu and Jew cannot consume some mammalian gelatins, the production of fish gelatin have gained attention (Benjakul et al., 2012). A popular freshwater fish in Thailand for fish ball production is clown featherback (Chitala ornata) because its meat can produce the product, which has a good and white gel (Kittiphattanabawon et al., 2015). From the production, the skin $(17-22 \%$ of total weight) was generated as a by-product. Although the skin was processed as a crispy fried fish skin, its market value is still low (Kittiphattanabawon et al., 2016). To increase the value of the skin, the production of gelatin is an alternative. Consequently, it can gain the higher benefit or revenue for processor. Generally, fish gelatin had poorer gel properties than mammalian gelatin because of lower imino acid content of fish gelatin. This causes a limited application of fish gelatin. Moreover, the properties of gelatin also depends on molecular weight distribution, which is affected by extraction conditions. Kittiphattanabawon et al. (2016) reported that gelatin extracted at higher temperature for longer time had higher yield and poorer gel properties. Additionally, the acid pretreatment process (swelling process) also affects yield and gel properties (Niu et al., 2013). Acid treatment can remove some undesired components, swell the skin and made gelatin able to be extracted effectively (Ahmad and Benjakul, 2011). However, use of excess acid concentration for swelling the skin may cause the loss of recoverable gelatin during swelling and washing processes (Binsi et al., 2009). Niu et al. (2013) reported that the use of more concentrated acid (0.01-0.2 M) could degrade $\beta$-chain and high molecular weight components (MW higher than $200 \mathrm{kDa}$ ). Recently, the effects of acid and/or alkali pretreatment process for gelatin extraction at different concentration on thermal properties, physicochemical properties and film forming ability have been reported (Al-Saidi et al., 2011; Jamilah et al., 2011; Niu et al., 2013). Nevertheless, there is no

\footnotetext{
*Corresponding author:

Phanat Kittiphattanabawon, Department of Food Science and Technology, Faculty of Technology and Community Development, Thaksin University, Phatthalung Campus, Phatthalung 93210, Thailand. Tel: 66-7460-9605 ext. 3319. Fax: 66-7469-3996.

E-mail: phanat@scholar.tsu.ac.th
} 
information regarding characteristics and gel properties of gelatin from the skin of clown featherback as affected by swelling time. Therefore, the objective of this study was to examine the effect of swelling time on characteristics and gel properties of gelatin from clown featherback skin.

\section{MATERIALS AND METHODS}

\section{Chemicals}

All chemicals were of analytical grade. Food grade bovine bone gelatin with the gel strength of 150-250 g was purchased from Halagel (Thailand) Co., Ltd., (Bangkok, Thailand).

\section{Preparation of clown featherback skin for gelatin extraction}

Skin of clown featherback (Chitala ornata) (0.7-1.5 kg/ fish) was obtained from a local fish ball processing plant at Talaadthai in Pathumthani province, Thailand. The residue meat and scale attached to the skin were removed by scratching using knife. The prepared skin was cleaned by cold tap water and placed in polyethylene bags (50-100 g/ bag). Then, the packed skin was stored at $-20{ }^{\circ} \mathrm{C}$ until used but not longer than 3 months. The prepared skin had moisture content of $65.72 \%$ as determined by AOAC method (AOAC, 2000). Prior to gelatin extraction, the frozen skin was thawed with running water until the core temperature of the skin reached $8-10^{\circ} \mathrm{C}$.

\section{Gelatin extraction}

Gelatin was extracted following the method of Kittiphattanabawon et al. (2016) with slight modifications. Non-collagenous protein was removed by soaking the skin in $0.1 \mathrm{M} \mathrm{NaOH}(1: 10, \mathrm{w} / \mathrm{v})$ for $40 \mathrm{~min}$ with continuous stirring using overhead stirrer (W20.n, IKA®-Werke GmbH \& CO.KG, Stanfen, Germany). The process was repeated 3 times. Then, the washing of alkali pretreated skin was done until the $\mathrm{pH}$ of wash water reached to 7-8. To swell the skin, it was soaked in $0.1 \mathrm{M}$ acetic acid $(1: 10, \mathrm{w} / \mathrm{v})$ for 15, 30, 60, 120 and 240 min with continuous stirring at a speed of $100 \mathrm{rpm}$, followed by washing thoroughly with tap water until $\mathrm{pH}$ of wash water reached to 6-7. The swelling solution was collected for further protein determination, which was proceeded by the method of Robinson and Hodgen (1940).

The gelatin from the swollen skin was extracted with distilled water at $45^{\circ} \mathrm{C}$ for $6 \mathrm{~h}$. The swollen skin to water ratio was $1: 4(\mathrm{w} / \mathrm{v})$. The mixture was continuously stirred using an overhead stirrer at a speed of $150 \mathrm{rpm}$, followed by filtration with two layers of cheesecloth. Then, $1 \mathrm{~g}$ of activated carbon was added into $100 \mathrm{~mL}$ of the filtrate to clarify the resulting solution. Then, the mixtures were filtered through Whatman No.4 filter paper (Whatman
International, Ltd., Maidstone, England). Finally, the resulting gelatin solution was dried by a freeze-dryer (CoolSafe 55, ScanLaf A/S, Lynge, Denmark). The resulting gelatin samples were subjected to determine gelatin recovery and analysis.

\section{Determination of gelatin recovery}

Hydroxyproline content in the skin and gelatin were determined according to the method of Bergman and Loxley (1963). To calculate the gelatin recovery, the equation below was used.

$$
\operatorname{Recov} \operatorname{ery}(\%)=\frac{\begin{array}{c}
100 \times H y p_{\text {gelatin }} \times \\
\text { gelatinobtained }
\end{array}}{\begin{array}{l}
\text { Hyp skin } \times \\
\text { skin used for extraction }
\end{array}}
$$

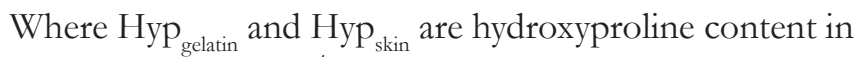
gelatin and skin ( $\mathrm{mg} / \mathrm{g}$ sample), respectively.

SDS-polyacrylamide gel electrophoresis (SDS-PAGE) SDS-PAGE was performed by the method of Laemmli (1970) using 7.5\% separating gel and 4\% stacking gel. To prepare sample, the samples $(60 \mathrm{mg})$ were dissolved in $5 \%$ SDS solution $(10 \mathrm{~mL})$ and boiled for $1 \mathrm{~min}$. The solution was centrifuged at $8500 \times \mathrm{g}$ for 5 min using a microcentrifuge (MIKRO20, Hettich Zentrifugan, Germany) to remove undissolved matter. The solubilized samples were mixed at $1: 1(\mathrm{v} / \mathrm{v})$ ratio with sample buffer (0.5 M tris- $\mathrm{HCl}, \mathrm{pH} 6.8$ containing 4\% SDS and 20\% glycerol) prior to loading in the SDS-polyacrylamide gel. The molecular weight of proteins obtained were estimated by comparing with High-molecular-weight protein markers (GE Healthcare UK Limited, Buckinghamshire, UK).

\section{Determination of gel properties Gel strength}

Gelatin was dissolved in distilled water at $60^{\circ} \mathrm{C}$ and gently stirred until gelatin was completely solubilized to obtain gelatin concentration of $6.67 \%(\mathrm{w} / \mathrm{v})$. Gel strength was determined according to the British Standard 757: 1975 method (BSI, 1975).

\section{Gelling temperature and time}

Gelatin solution $(6.67 \%, \mathrm{w} / \mathrm{v})$ was prepared in the same manner as previously described. The measurement of gelling time and temperature of gelatin were proceeded by the HAAKE RheoStress ${ }^{\mathrm{TM}} 1$ rheometer (Karlsruhe, Germany) equipped with a cone-plate geometry. The diameter and angle of plate and cone are $35 \mathrm{~mm}$ and $1^{\circ}$, respectively.

To measure gelling temperature and time, the gelatin solution $(6.67 \%, \mathrm{w} / \mathrm{v})$ was preheated at $60^{\circ} \mathrm{C}$ and subjected 
to a controlled stress rheometer equipped with a $3.5 \mathrm{~cm}$ parallel plate with the gap between plates of $1.0 \mathrm{~mm}$. The measurement condition was detailed as previously described (Kittiphattanabawon et al., 2016).

The functions between phase angle $(\delta)$ and temperature and phase angle and time were plotted to determine gelling temperature and time, respectively. The temperature and time at which $\tan \delta$ became 1 or $\delta$ was $45^{\circ}$ were recorded as gelling temperature and time, respectively.

\section{Microstructure of gelatin gel}

Microstructure of gelatin gel was visualized using a scanning electron microscopy (SEM). Gelatin gels were prepared following the method of Kittiphattanabawon et al. (2016). Briefly, gelatin gels were fix with $2.5 \%(\mathrm{v} / \mathrm{v})$ glutaraldehyde in $0.2 \mathrm{M}$ phosphate buffer $(\mathrm{pH} 7.2)$ and dehydrated in serial concentration of ethanol $(50,70,80$, 90 and $100 \%, v / v)$. The dried samples were mounted on a bronze stub and sputter-coated with gold (Sputter coater SPI-Module, West Chester, PA, USA). The specimens were observed with a scanning electron microscope (JEOL JSM$5800 \mathrm{LV}$, Tokyo, Japan) at an acceleration voltage of $10 \mathrm{kV}$ with magnification of 3000X.

\section{Statistical analysis}

The study factor of this experiment is swelling time ( 0 , 15, 30, 60, 120 and $24 \mathrm{~min}$ ). The experiments were run in triplicate using three different lots of samples. The data presented as means \pm standard deviation were analyzed using analysis of variance (ANOVA) and the mean comparisons were carried out by Duncan's multiple range (Steel and Torrie, 1980). The statistical Package for Social Sciences (SPSS for windows: SPSS Inc., Chicago, IL, USA) were used as a software for statistical analysis.

\section{RESULTS AND DISCUSSION}

\section{Recovery of gelatin}

The recovery of gelatin extracted from the clown featherback skin swollen with $0.1 \mathrm{M}$ acetic acid at different times and protein loss according to swelling time are shown in Fig. 1. Swelling is an important process for gelatin extraction due to protein unfolding by disruption of non-covalent bonding and predispose the collagen to subsequent extraction and solubilization (Benjakul et al., 2012). The result showed that the recovery of gelatin decreased as swelling time increased $(P<0.05)$. The highest and lowest recoveries of gelatin were respectively found when the gelatin extracted from skin swollen for 15 and $30 \mathrm{~min}(80.98-81.52 \%)$ and $240 \mathrm{~min}(40.47 \%)$. This results might be caused by solubilization of collagen during swelling process as noticed by increasing of protein loss in swelling solution as swelling time increased (Fig. 1). The possibility of loss during the later washing process is not considered because gelatin obtained from the nonswollen skin showed the lowest recovery $(9.80 \%)(P<0.05)$. Additionally, water had hardly penetrated the skin and it resulted in water cannot efficiently solubilize collagen in the skin during gelatin extraction. That is why the lowest gelatin recovery was found in the gelatin extracted from non-swollen skin. Therefore, the swelling time is crucial in order to minimize the loss of gelatin during swelling and the later washing process.

\section{Protein patterns}

Protein patterns of gelatin extracted from non-swollen skin and skin swollen with $0.1 \mathrm{M}$ acetic acid for 15, 30, 60, 120 and $240 \mathrm{~min}$ are shown in Fig. 2. In the gelatin extracted from non-swollen skin, some of $\alpha 1$-chain and all of $\alpha 2$ chain, $\beta$-chain and high molecular weight components

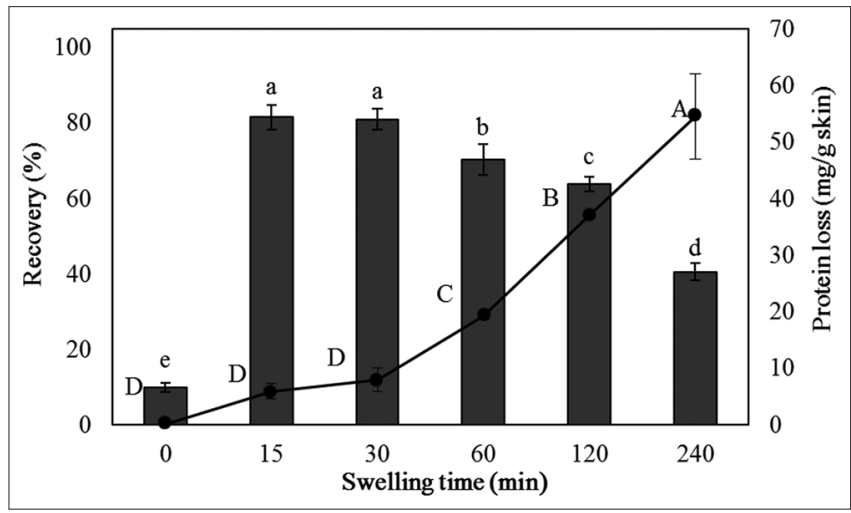

Fig 1. Recovery (bar) of gelatin from the skin of clown featherback obtained from swollen skin with $0.1 \mathrm{M}$ acetic acid for various times and protein loss during swelling process (line) for various times. Different lowercases and uppercases on the bars and line, respectively, denote the significant differences $(P<0.05)$.

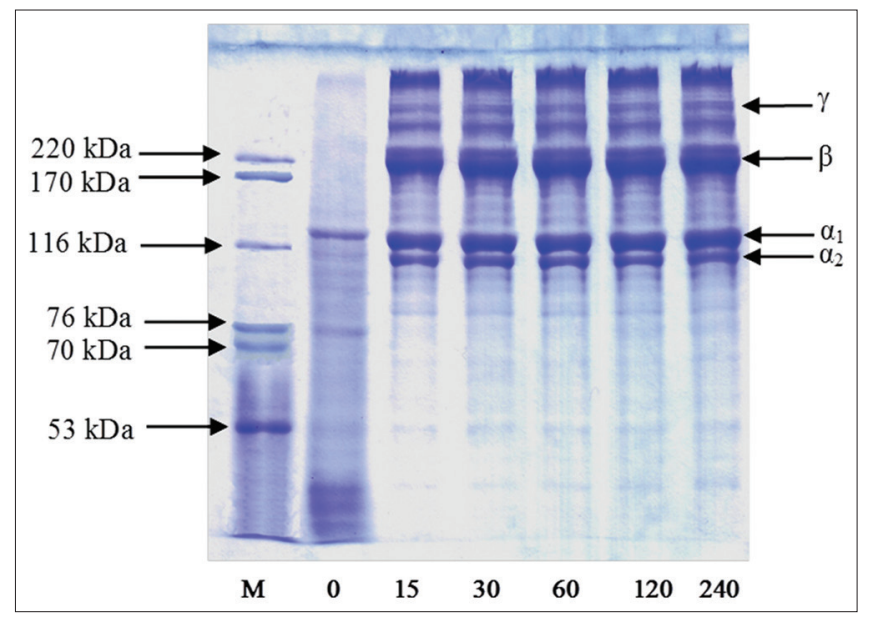

Fig 2. SDS-PAGE patterns of gelatin from the skin of clown featherback obtained from swollen skin with $0.1 \mathrm{M}$ acetic acid for various times. $\mathrm{M}$ denotes high molecular weight markers. The numbers mean swelling time. 
were degraded into $74.9,32.7,29.4$ and $27.0 \mathrm{kDa}$. It might be caused by hydrolysis of endogenous proteinase during water extraction $\left(\right.$ at $\left.45^{\circ} \mathrm{C}\right)$. The $\mathrm{pH}$ of non-swollen skin was about 7.5 , which might be the optimum $\mathrm{pH}$ of endogenous proteinase. Intarasirisawat et al. (2007) reported that the optimum $\mathrm{pH}$ of endogenous proteinase in bigeye snapper skin was 7.5 and it could be activated at temperature ranging from $50-70{ }^{\circ} \mathrm{C}$. From the result, the degradation of $\alpha$-, $\beta$ - and $\gamma$-components were found in the gelatin obtained from non-swollen skin. However, no difference in protein patterns were observed among gelatin extracted from swollen skin with $0.1 \mathrm{M}$ acetic acid for different periods of times. All gelatins extracted from swollen skin contained $\alpha 1$-, $\alpha 2$ - and $\beta$-chains as the major components indicating that swelling time did not affect the major component of gelatin ( $\alpha$-, $\beta$ - and $\gamma$-chains). However, type and concentration of acid for swelling the skin had the influence on the major components of gelatin as reported by Niu et al. (2013) who found that the swelling skin for extraction of gelatin from tilapia using concentration of citric acid and $\mathrm{HCl}$ higher than $0.05 \mathrm{M}$ resulted in the band intensity of $\beta$-chain and high molecular weight components (MW higher than $200 \mathrm{kDa}$ ) decreased, however the decreasing in those components was not noticeable when the skin was swollen with acetic acid $(0.05 \mathrm{M}$ to $0.20 \mathrm{M})$.

\section{Gel strength of gelatin gel}

Gel strength of gelatin gel obtained from gelatin extracted from non-swollen skin and skin swollen with $0.1 \mathrm{M}$ acetic acid for 15, 30, 60, 120 and 240 min are shown in Fig. 3. There was no significant difference in gel strength among gelatin gel obtained from gelatin extracted from swollen skin for different times (330-342 g). This was possibly due to acid is not strong enough to degrade $\alpha$ - and $\beta$-chains, however, swelling the skin for longer time caused more the loss of gelatin yield during swelling and washing processes as shown in Fig. 2. On the other hand, gelatin extracted from non-swollen skin showed extremely low gel strength (82 g). It was probably due to the degradation of $\alpha$ - and $\beta$-chains by endogenous proteinase during extraction. The presence of protein degradation fragments may reduce the ability of $\alpha$-chains to anneal correctly during stabilization overnight and thus hindering the growth of the existing nucleation sites (Ledward, 1986; Normand et al., 2000; Taheri et al., 2009). Benjakul et al. (2012) reported that gelatin molecules with the shorter chains generated by endogenous proteinase are not able to form the strong inter-junction zone, especially via hydrogen bond or other weak bonds such as hydrophobic interaction or ionic interaction. As a consequence, a weaker network develops. The results were in accordance with their protein patterns (Fig. 2). The existence of $\alpha$ - and $\beta$-chains was considered as a factor for determining the gel strength. Kittiphattanabawon et al. (2016) reported that gelatin from the skin of clown featherback extracted at lower temperature $\left(45^{\circ} \mathrm{C}\right)$ contained higher amount of $\alpha$-, $\beta$ - and $\gamma$-components showed much higher gel strength than that extracted at higher temperature $\left(85^{\circ} \mathrm{C}\right)$, which contained lower amount of those components. Thus, the swelling time did not affect the gel strength of gelatin.

\section{Gelling temperature and time}

Gelling temperature and time are shown in Fig. $4 \mathrm{a}$ and $4 \mathrm{~b}$, respectively. For the mechanism of gelatin gelation, an aqueous solution of gelatin becomes viscous at temperature above its melting temperature. On cooling, the gelatin solution starts to form transparent elastic thermoreversible gels when the temperature is below the setting temperature (Babin and Dickinson, 2001; Normand et al., 2000). The gelatin extracted from swollen skin had gelling temperature ranging from $23.29-23.76{ }^{\circ} \mathrm{C}$. No difference in gelling temperature was found among gelatin extracted from swollen skin for different times $(P>0.05)$. However, the marked low gelling temperature was found in gelatin extracted from non-swollen skin $\left(12.80^{\circ} \mathrm{C}\right)$. For gelling time (Fig. 4b), gelatin extracted from non-swollen skin was not able to set within $60 \mathrm{~min}$, while gelling time of that extracted from swollen skin were ranging from 12.03-12.23 min. No difference in gelling time was observed between bovine gelatin and gelatin extracted from swollen skin. Additionally, gelling time of gelatin extracted from skin swollen for different time were not significant different $(P>0.05)$. The gelling temperature and time of extracted gelatin were correlated with their molecular weight distribution (Fig. 2) and gel strength (Fig. 3). Muyonga et al. (2004) reported that the molecular weight and the relative content of $\alpha$-, $\beta$ - and $\gamma$-chains of gelatin affected to its setting temperature. The gelatin extracted from non-swollen skin had a higher degradation, which might be caused by hydrolysis of endogenous proteinase. These fragments cannot form

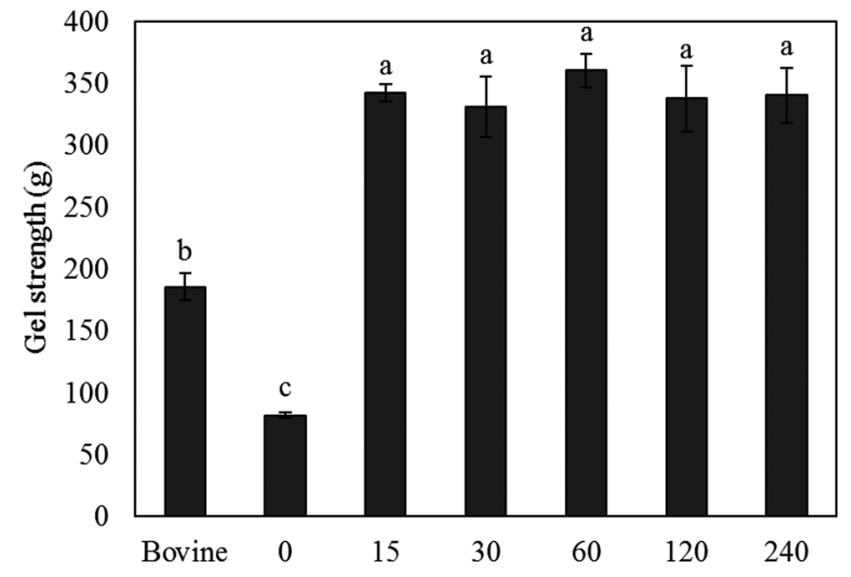

Fig 3. Gel strength of gels of gelatin from the skin of clown featherback obtained from swollen skin with $0.1 \mathrm{M}$ acetic acid for various times. Different letters on the bars denote the significant differences $(P<0.05)$. Bovine is commercial gelatin from bovine bone. 


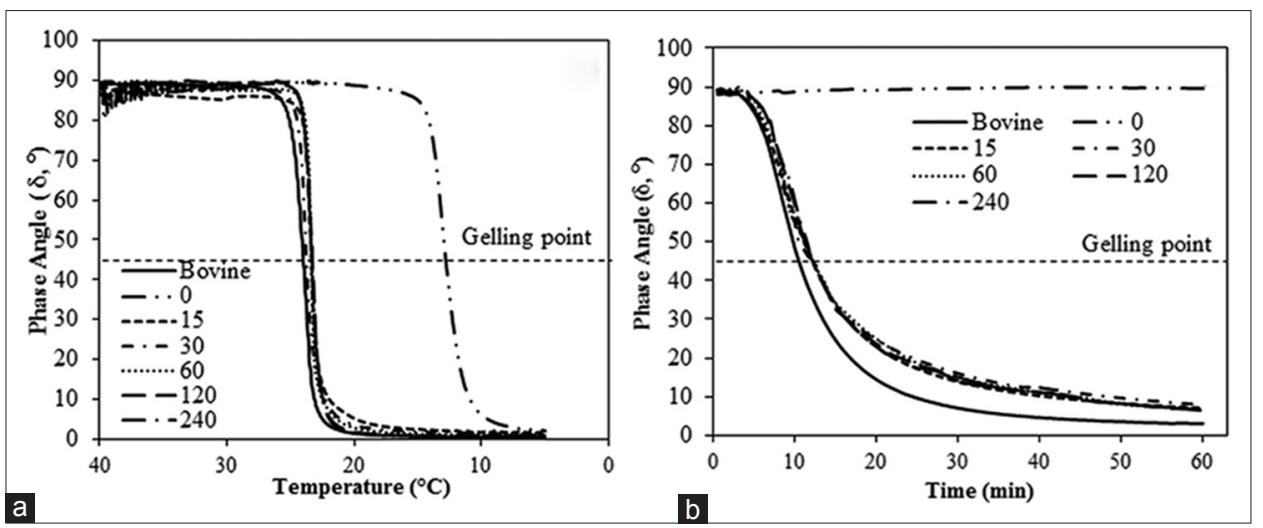

Fig 4. Changes in phase angle $(\delta)$ of solution as a function of temperature (a) and time (b) of gelatin from the skin of clown featherback obtained from swollen skin with $0.1 \mathrm{M}$ acetic acid for various times.

the junction zone as effectively. As a consequence, the formation of a gel network of those fragments needed a lower temperature for alignment and connection between chains, resulting in a poor gel was formed or those fragments was not able to set at room temperature $\left(25^{\circ} \mathrm{C}\right)$ within $60 \mathrm{~min}$. These results indicate that the different swelling time did not affect the setting temperature and time.

\section{Microstructure of gelatin gel}

Microstructures of gelatin gel obtained from gelatin extracted from non-swollen skin and swollen skin using $0.1 \mathrm{M}$ acetic acid for 15 and $240 \mathrm{~min}$ are shown in Fig. 5. Generally, the conformation and chain length of protein in gel matrix and the presence of $\alpha$-, $\beta$ - and $\gamma$-chains directly governed the gel strength of gelatin (Benjakul et al., 2012). All microstructure of gelatin gels were sponge-like. The gels obtained from gelatin extracted from swollen skin were more ordered and denser network, finer strand and smaller void than that obtained from bovine gelatin and gelatin extracted from non-swollen skin, respectively. Additionally, no difference in microstructure of gel was found among gelatin extracted from swollen condition. The microstructure of gels was coincidental with the protein patterns (Fig. 2) and gel strength (Fig. 3). The finer and denser structure of the gel network reflected to the higher gel strength (Fig. 3). The result indicated that the swelling time did not have an impact on the chain length of major component of gelatin, which directly affected the gel strength of gelation.

\section{CONCLUSIONS}

The acid swelling process facilitated the skin swelling and gelatin extraction by hot water. The swelling time higher than $30 \mathrm{~min}$ did not affect the protein patterns and gel properties, but it was observed a decreasing gelatin recovery. Therefore, the recommended swelling time for gelatin extraction from the skin of clown featherback is

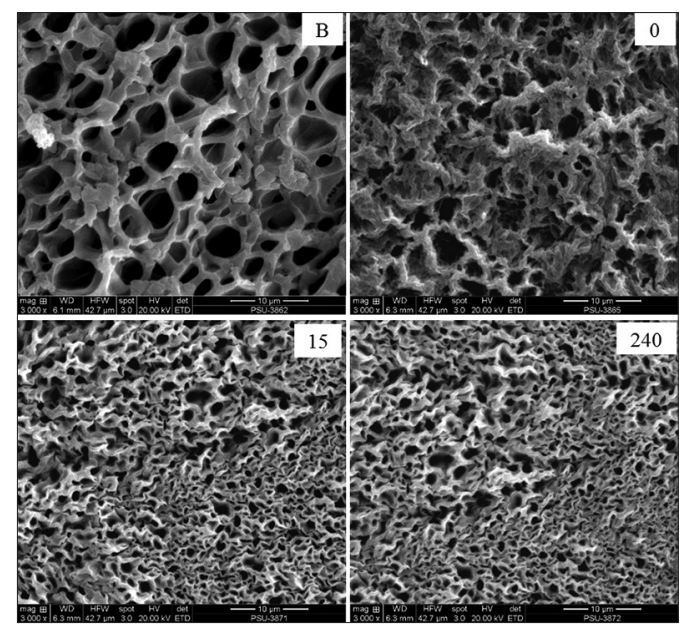

Fig 5. Microstructure of gels from gelatin from the skin of clown featherback obtained from swollen skin with $0.1 \mathrm{M}$ acetic acid for various times. Magnification: $3000 \times$. The numbers mean swelling time. $\mathrm{B}$ denotes commercial gelatin from bovine bone.

15 min when $0.1 \mathrm{M}$ acetic acid is used as swelling solution. These results could be a benefit for production of gelatin from clown featherback skin to minimized swelling time coupled with the highest yield.

\section{ACKNOWLEDGMENTS}

This research was supported by Higher Education Research Promotion (HERP) and National Research Universities (NRU), the Office of the Higher Education Commission and Thaksin University [grant number: 184787]. Thanks to Faculty of Agro-industry, Prince of Songkla University for the permission to use facilities for this research.

\section{Authors' contributions}

Phanat Kittiphattanabawon designed and conducted the experiment, analyzed, interpreted and concluded the result. Soottawat Benjakul gave a suggestion for experimental design and supported instrument for analysis. 


\section{REFERENCES}

Ahmad, M. and S. Benjakul. 2011. Characteristics of gelatin from the skin of unicorn leatherjacket (Aluterus monoceros) as influenced by acid pretreatment and extraction time. Food Hydrocoll. 25: 381-388.

Al-Saidi, G., M. S. Rahman, A. Al-Alawi and N. Guizani. 2011. Thermal characteristics of gelatin extracted from shaari fish skin effects of extraction conditions. J. Therm. Anal. Calorim. 104: 593-603.

AOAC. 2000. Official Methods of Analysis. $17^{\text {th }}$ ed. Association of Official Ananlytical Chemists Inc., Arlington, VA.

Babin, H. and E. Dickinson. 2001. Influence of transglutaminase treatment on the thermoreversible gelation of gelatin. Food Hydrocoll. 15: 271-276.

Benjakul, S., P. Kittiphattanabawon and J. M. Regenstein. 2012. Fish gelatin. In: B. K. Simpson, G. Paliyath, L. M. L. Nollet, S. Benjakul and F. Toldrá (Eds.), Food Biochemistry and Food Processing, John Wiley \& Sons, Inc., lowa, pp. 388-405.

Bergman, I. and R. Loxley. 1963. Two improved and simplified methods for the spectrophotometric determination of hydroxyproline. Anal. Chem. 35: 1961-1965.

Binsi, P. K., B. A. Shamasundar, A. O. Dileep, F. Badii and N. K. Howell. 2009. Rheological and functional properties of gelatin from the skin of bigeye snapper (Priacanthus hamrur) fish: Influence of gelatin on the gel-forming ability of fish mince. Food Hydrocoll. 23: 132-145.

BSI. 1975. Methods for Sampling and Testing Gelatin (Physical and Chemical Methods), BSI, London.

Intarasirisawat, R., S. Benjakul, W. Visessanguan, T. Prodpran, M. Tanaka and N. K. Howell. 2007. Autolysis study of bigeye snapper (Priacanthus macracanthus) skin and its effect on gelatin. Food Hydrocoll. 21: 537-544.

Jamilah, B., K. W. Tan, M. R. Umi Hartina and A. Azizah. 2011. Gelatins from three cultured freshwater fish skins obtained by liming process. Food Hydrocoll. 25: 1256-1260.
Kittiphattanabawon, P., S. Benjakul, S. Sinthusamran and H. Kishimura. 2015. Characteristics of collagen from the skin of clown featherback (Chitala ornata). Int. J. Food Sci. Technol. 50: 1972-1978.

Kittiphattanabawon, P., S. Benjakul, S. Sinthusamran and H. Kishimura. 2016. Gelatin from clown featherback skin: Extraction conditions. LWT Food Sci. Technol. 66: 186-192.

Laemmli, U. K. 1970. Cleavage of structural proteins during the assembly of the head of bacteriophage T4. Nature. 227: 680-685.

Ledward, D. A. 1986. Gelation of gelatin. In: Mitchell, J. R. and D. A. Ledward (Eds.), Functional Properties of Food Macromolecules, Elsevier Applied Science, London, pp. 171-201.

Muyonga, J. H., C. G. B. Cole and K. G. Duodu. 2004. Extraction and physico-chemical characterisation of Nile perch (Lates niloticus) skin and bone gelatin. Food Hydrocoll. 18: 581-592.

Niu, L., X. Zhou, C. Yuan, Y. Bai, K. Lai, F. Yang and Y. Huang. 2013. Characterization of Tilapia (Oreochromis niloticus) skin gelatin extracted with alkaline and different acid pretreatments. Food Hydrocoll. 33: 336-341.

Normand, V., S. Muller, J. C. Ravey and A. Parker. 2000. Gelation kinetics of gelatin: A master curve and network modeling. Macromolecules. 33: 1063-1071.

Robinson, H. W. and C. G. Hodgen. 1940. The biuret reaction in the determination of serum protein. I. A study of the condition necessary for the production of the stable color which bears a quantitative relationship to the protein concentration. J. Biol. Chem. 135: 707-725.

Steel, R. G. D. and J. H. Torrie. 1980. Principles and Procedures of Statistics: A Biometrical Approach. $2^{\text {nd }}$ ed. McGraw-Hill, New York.

Taheri, A., A. M. A. Kenari, A. Gildberg and S. Behnam. 2009. Extraction and physicochemical characterization of greater lizardfish (Saurida tumbil) skin and bone gelatin. J. Food Sci. 74: E160-E165. 